\title{
Influence of saliva contamination on the shear bond strength of adhesives on enamel
}

\author{
Tatiana Feres Assad-Loss'1, Mônica Tostes² ${ }^{2}$ José Nelson Mucha ${ }^{3}$
}

Objective: To evaluate shear bond strength of 3 adhesive systems (Single Bond, Transbond ${ }^{\mathrm{TM}}$ MIP and Transbond $^{\mathrm{TM}} \mathrm{XT}$ ) applied on bovine enamel under saliva contamination condition.

Method: One hundred and twenty enamel surfaces of bovine incisors were divided into 6 groups $(n=20)$ according to the adhesive system used (Transbond ${ }^{\mathrm{TM}}$ XT, Transbond ${ }^{\mathrm{TM}}$ MIP and Single Bond) with or without saliva contamination. For each adhesive system, there were two groups defined as no contamination group (NC): $37 \% \mathrm{H}_{3} \mathrm{PO}_{4}$ conditioning for 30 seconds and two layers of adhesive systems; saliva contamination group (SC): After the first adhesive layer application, the examined areas were contaminated with saliva. Samples were mounted appropriately for testing and stored in deionized water at $37^{\circ} \mathrm{C}$ for 7 days. Samples were then submitted to shear bond strength trials at a speed of $0.5 \mathrm{~mm} / \mathrm{min}$. The Adhesive Remnant Index (ARI) was evaluated under stereomicroscopy. Twoway analysis of variance and the Tukey test were used to compare mean values $(\alpha=0.05)$.

Results: Groups XT (NC) $=26.29 \pm 7.23$; MIP $(\mathrm{NC})=24.47 \pm 7.52$ and $\mathrm{SB}(\mathrm{NC})=32.36 \pm 4.14$ XT $(\mathrm{SC})=19.59 \pm 6.76$; $\mathrm{MIP}(\mathrm{SC})=18.08 \pm 6.39$ and $\mathrm{SB}(\mathrm{SC})=18.18 \pm 7.03 \mathrm{MPa}$. ARI 0 and 1 were the most prevalent scores in all study groups examined.

Conclusion: Saliva contamination significantly decreased bond strength of the three adhesive systems examined ( $\mathrm{p}<0.05$ ). However, the comparison of groups with and without saliva contamination did not reveal any significant differences, and, therefore, the three systems may be considered equivalent.

Keywords: Enamel bonding. Saliva contamination. Shear bond strength.

${ }^{1}$ MSc in Dentistry, UFF. Specialist in Orthodontics, UFF. Specialist in Pediatric Dentistry, UFF.

${ }^{2}$ Associate Professor of Pediatric Dentistry, UFF.

${ }^{3}$ Head Professor of Orthodontics, UFF.

\author{
How to cite this article: Assad-Loss TF, Tostes M, Mucha JN. Influence of saliva \\ contamination on the shear bond strength of adhesives on enamel. Dental Press J \\ Orthod. 2012 Mar-Apr; 17(2):30.el-6. \\ Submitted: August 12, 2008 - Revised and accepted: November 24, 2008 \\ " The authors report no commercial, proprietary, or financial interest in the products \\ or companies described in this article. \\ Contact address: Tatiana Feres Assad-Loss \\ Praia de Icaraí 469 - Ap. 602 - CEP: 24230-008 - Niterói / RJ - Brazil \\ E-mail: tatianaassad@yahoo.com.br
}

E-mail: tatianaassad@yahoo.com.br 


\section{INTRODUCTION}

Adhesive failures may occur during orthodontic bracket bonding due to saliva contamination. The development of hydrophilic primers has minimized this problem because they ensure acceptable bond strength even in a moist environment. The formulation of hydrophilic primers includes ethanol and acetone, substances that can displace moisture from the enamel surface. One of these primers, Transbond ${ }^{\mathrm{TM}}$ MIP (3M Unitek Dental Products, Monrovia, CA, USA) is recommended for bonding in a moist environment either with or without light-curing adhesives.

Studies using Transbond ${ }^{\mathrm{TM}}$ MIP adhesive system found acceptable strength values for bonding in contaminated environments. ${ }^{5,6}$ However, when used in moist environments, its advantages over Transbond ${ }^{\mathrm{TM}}$ XT (3M Unitek Dental Products, Monrovia, CA), a conventional adhesive system, remain controversial.,15,16

In a dry environment, both have similar bond strength, ${ }^{4,5,15,17}$ but Transbond ${ }^{\mathrm{TM}}$ MIP may present a significantly higher bond strength than necessary for bonding (18.31 MPa) ${ }^{13}$ which may damage the enamel during debonding. Adhesive materials should have shear bond strengths compatible to the clinical needs. ${ }^{12}$

According to Grandhi et al, ${ }^{5}$ the hydrophilic Transbond ${ }^{\mathrm{TM}}$ MIP adhesive system is chemically identical to the Single Bond system (3M, St. Paul, MN, USA), but the effect of contamination when using Single Bond has not been fully defined.

This study evaluated the shear bond strength of three adhesive systems, Single Bond, Transbond ${ }^{\mathrm{TM}}$ $\mathrm{XT}$ and Transbond ${ }^{\mathrm{TM}}$ MIP, on bovine enamel with and without saliva contamination.

\section{MATERIAL AND METHODS}

This study was approved by the Ethics in Research Committee of the Center of Medical Sciences, Universidade Federal Fluminense, Niterói, Brazil (CEP CMM/HUAP n. 36/03).

\section{Shear bond strength trial}

The root of 120 bovine incisors stored in distilled water at room temperature until the time of use were separated from the crowns using a double-faced diamond disk (KG Sorensen, Curitiba, Brazil) mounted on a micro motor handpiece under constant cooling (Figs 1A and 1B). The buccal surfaces were polished under cooling (DPU-10, Struers, Copenhagen, Denmark) using 400 and 600-grit silicon carbide sanding discs to produce a flat and smooth enamel surface.

The teeth were embedded in polystyrene resins (UC 2120) into PVC cylinders, with the flat enamel surfaces facing the base of the cylinders (Figs $1 \mathrm{C}$ and 1D). After the polystyrene resin polymerization, the enamel surfaces were polished with a 600-grit sanding paper to standardize the smear layer. The enamel surfaces underwent prophylaxis with pumice and water applied with a rubber cup at low speed for $15 \mathrm{sec}-$ onds and rinsed with water-air sprays for 30 seconds (Fig 1D). The specimens were randomly divided into six groups ( $n=20)$ according to the adhesive system used (Table 1 and Fig 2).

\section{Groups XT (NC), MIP (NC) and SB (NC)}

The enamel surfaces were etched by applying $37 \%$ phosphoric acid for 30 seconds, rinsed for $60 \mathrm{sec}-$ onds and dried for 20 seconds (Fig 2A); then, the adhesives were applied according to the instruction of the manufacturer (Fig 2B).

\section{Groups XT (SC), MIP (SC) and SB (SC)}

After receiving the same surface treatment used in the previous groups (Fig 2A) and the application of an adhesive layer (Fig 2B), the surfaces were contaminated for 10 seconds with non-stimulated fresh saliva collected from the operator after brushing the teeth with a non-fluoride toothpaste after one-hour fasting lapse (Fig 2C). Excess saliva was removed with gauze, the specimen was air sprayed for 3 seconds, and a new adhesive layer was applied.

After adhesive application, $3 \times 3 \mathrm{~mm}$ cylinders

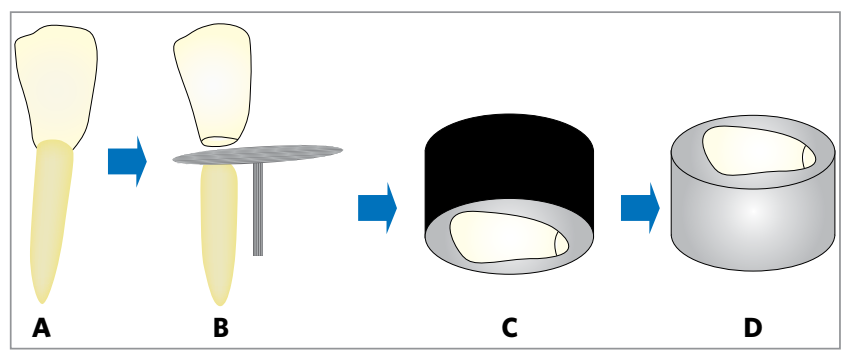

Figure 1 - Schematic representation of storage of 120 bovine incisors (A); roots separated from crowns using double-faced diamond disc (B). Teeth embedded in polystyrene resin into PVC cylinders, with the enamel surfaces facing the base of cylinders (C). After curing polystyrene resin, enamel surfaces were polished for surface standardization (D) 
Table 1- Data (MPa \pm standard deviation) of the Transbond XT, Transbond MIP and Single Bond adhesive systems with no contamination (NC) or with saliva contamination (SC).

\begin{tabular}{ccc}
\hline Adhesive system & NC & SC \\
\hline XT & a $26.29 \pm 7.23$ & b.c19.59 \pm 6.76 \\
MIP & a.b $24.47 \pm 7.52$ & $\mathrm{c} 18.08 \pm 6.39$ \\
SB & $32.36 \pm 4.14$ & $\mathrm{c} 18.18 \pm 7.03$ \\
\hline
\end{tabular}

Data followed by the same letter were not statistically different $(p<0.05)$.

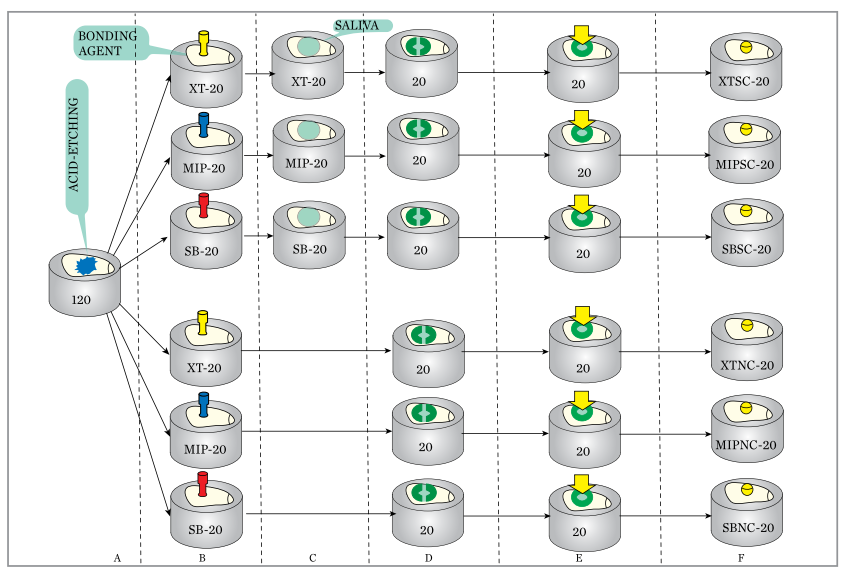

Figure $\mathbf{2}$ - Schematic sequence of etching with $37 \%$ phosphoric acid for 30 seconds (A) Specimens divided into 6 groups, and application of 3 adhesive systems according to manufacturer instructions (B). Contamination of surfaces in SC groups with saliva (C) Adaptation of metal matrix (D), insertion of Transbond XT composite resin into matrix (E) and cylinders placement on enamel surface for testing $(\mathbf{F})$

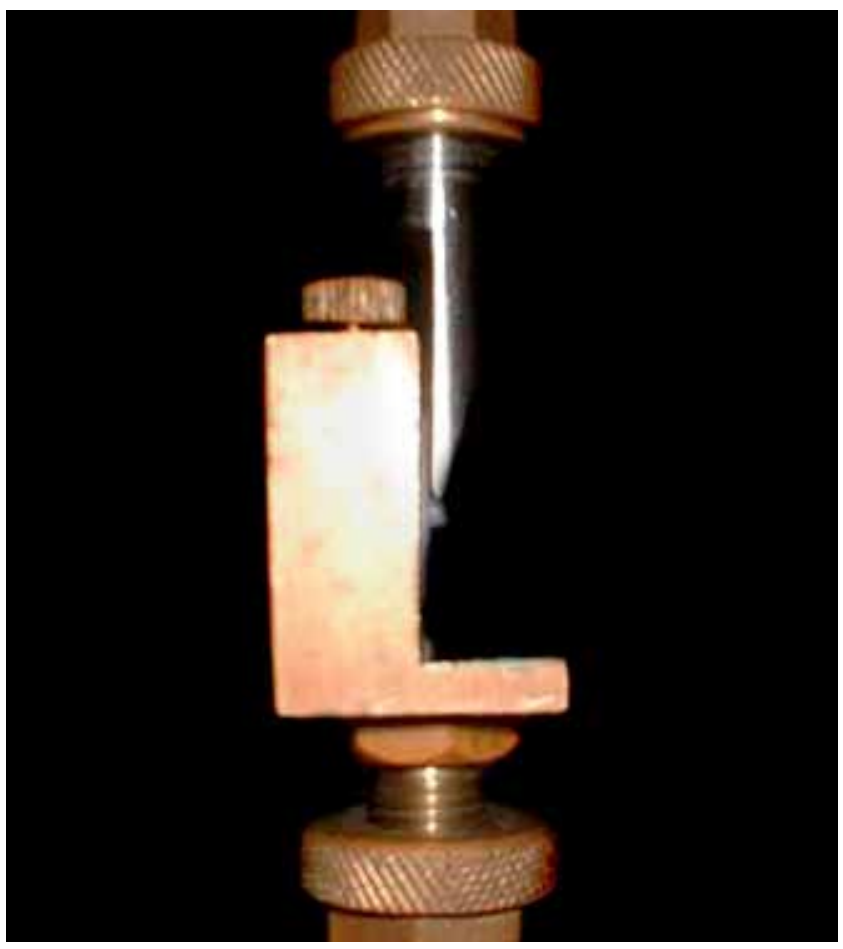

Figure 3 - Specimen being submitted to shear bond strength trials (DL 10,000, EMIC, Curitiba, Brazil) at cross-head speed of $5 \mathrm{~mm} /$ min and $50 \mathrm{~N}$ load. of Transbond ${ }^{\mathrm{TM}} \mathrm{XT}$ composite resin were prepared and placed in the center of the enamel surfaces (Fig $2 \mathrm{E}$ and $2 \mathrm{~F}$ ). The cement was inserted, in a single increment, into a metal matrix divided into two parts (Fig 2D) and light cured for 20 seconds.

After storage in distilled water at $37^{\circ} \mathrm{C}$ for 7 days, the specimens underwent shear bond strength trials (DL 10.000, EMIC, Curitiba, Brazil) at a cross-head speed of $0.5 \mathrm{~mm} / \mathrm{min}$ and $50 \mathrm{~N}$ load (Fig 3). Data were collected for means and standard deviations analysis, as shown in Table 1.

\section{Evaluation of adhesive remnant index score}

After the shear bond strength trial, the enamel surfaces were examined under stereomicroscopy (Coleman) at 15x magnification to evaluate adhesive remnants according to the adhesive remnant index (ARI) score: ${ }^{1}$

1 - Less than half of the adhesive remained on the surface;

2 - More than half of the adhesive remained on the surface.

The type of failures at the interface was also evaluated using the following criteria:

A - Cohesive fracture - with damage to the enamel; B-Adhesive Fracture - without damage to the enamel.

\section{STATISTICAL ANALYSIS}

The shear bond strength data (in $\mathrm{MPa}$ ) were analyzed using the Shapiro-Wilk test to normal distribution and the Levene test for homogeneity variance. As the normal distribution was confirmed, data were analyzed using two-way analysis of variance and the Tukey test to compare means $(\alpha=0.05)$.

\section{RESULTS}

Mean bond strength data (MPa) are shown in Table 1. Analysis of variance revealed a significant difference in surface treatment $\left(\mathrm{p}=3.15 \times 10^{-11}\right)$. There was a statistically significant reduction in bond strength in all adhesive systems under test when the enamel surface was contaminated with saliva. There was also a statistically significant difference in the comparison of adhesive systems $(\mathrm{p}<0.05)$, as shown in Table 1 and Figure 4. The Tukey test revealed that the SB(NC) system had the best performance $(32.36 \pm 4.14)$ and a 


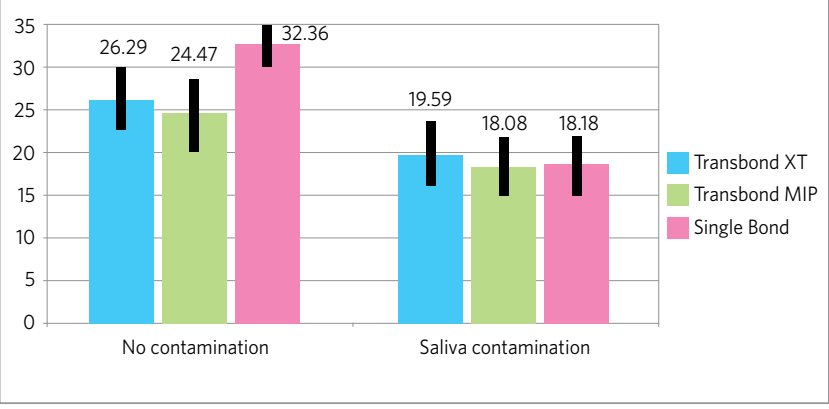

Figure 4 - Means and standard deviations of the 3 systems under study, with and without saliva contamination.

Table 2 - Shows the adhesive remnant index (ARI) score and the number of cohesive failures.

\begin{tabular}{cccccc} 
Groups & \multicolumn{3}{c}{ ARI } & \multicolumn{2}{c}{ Cohesive failures } \\
& 0 & 1 & 2 & 3 & \\
XT NC & 7 & 8 & 0 & 3 & 2 \\
XT SC & 11 & 8 & 0 & 0 & 1 \\
MIP NC & 4 & 8 & 1 & 1 & 6 \\
MIP SC & 8 & 11 & 1 & 0 & 0 \\
SB NC & 0 & 16 & 3 & 0 & 1 \\
SB SC & 12 & 7 & 0 & 0 & 1 \\
\hline
\end{tabular}

significantly higher bond strength than the other adhesives with no contamination. Transbond ${ }^{\mathrm{TM}} \mathrm{XT}$ and Transbond $^{\mathrm{TM}}$ MIP systems had no statistically significant differences in the groups with no saliva contamination (NC). In the groups with saliva contamination (SC), there were no differences between the adhesive systems under study.

Data followed by the same letter were not statistically different $(\mathrm{p}<0.05)$.

Table 2 shows the adhesive remnant index (ARI) score and the number of cohesive failures.

The most prevalent ARI scores were 0 and 1 for all groups. The highest number of cohesive failures was in the Transbond ${ }^{\mathrm{TM}}$ MIP group with no saliva contamination (MIP NC) $(\mathrm{n}=6)$.

\section{DISCUSSION}

This study compared the shear bond strength of Single Bond, Transbond ${ }^{\mathrm{TM}}$ MIP and Transbond ${ }^{\mathrm{TM}}$ $\mathrm{XT}$ adhesive systems used together with the Transbond $^{\mathrm{TM}} \mathrm{XT}$ composite resin in an environment with or without saliva contamination.
Mean shear bond strength data for the groups with no contamination (NC) were $26.3 \mathrm{MPa}, 24.5 \mathrm{MPa}$ and 32.4 MPa for Transbond ${ }^{\mathrm{TM}} \mathrm{XT}$, Transbond ${ }^{\mathrm{TM}}$ MIP and Single Bond, respectively. Regarding groups with saliva contamination, mean data were $19.6 \mathrm{MPa}$, 18.1 MPa and 18.2 MPa. The results showed no statistically significant differences for the comparison of the materials tested, which indicated that they are equivalent, except for the group of the Single Bond system with no contamination, which showed a very high shear bond strength mean, probably due to the adhesive light-curing procedure before the composite resin specimen was inserted.

There was a statistically significant difference between systems when groups with and without saliva contamination were compared. Although the bond strength data in the saliva contamination groups were significantly lower than in the groups with no contamination, the results were still acceptable for orthodontic bracket bonding.

Other studies also found statistically significant differences between the Transbond ${ }^{\mathrm{TM}}$ MIP and the Transbond ${ }^{\mathrm{TM}} \mathrm{XT}$ in a dry environment., ${ }^{4,5,16}$

Enamel surface contamination may occur at two critical time points during bonding: After etching or after adhesive application. When that happens, bonding may be affected. ${ }^{4}$

Some studies found a greater decrease in bond strength when contamination occurred after acidetching; in such cases, re-etching of the enamel surface was necessary. ${ }^{5,14,16}$

The contamination of the etched area by saliva or blood leads to the sealing of most of the porosity created by enamel acid-etching, which prevents the penetration of the adhesive material, resulting in insufficient resin tags in both number and length, and compromises bonding. ${ }^{7}$

Other studies also found statistically significant differences when materials were compared before and after saliva contamination, with no differences regarding the material employed, ${ }^{6,16}$ although some studies have suggested differently about whether Transbond $^{\mathrm{TM}}$ MIP may be the best choice for moist environments. ${ }^{11}$

According to Grandi et al, ${ }^{5}$ the hydrophilic primer (Transbond ${ }^{\mathrm{TM}}$ MIP, 3M Unitek) is chemically identical to the dental adhesive that contains ethanol (Single 
Bond, 3M). In our study, bond strength results were similar for both materials when the enamel surface was contaminated with saliva, which suggests that Single Bond may be used as a replacement for Transbond ${ }^{\mathrm{TM}}$ MIP in a moist environment.

No similar comparison could be made in dry environments because the material was used strictly as recommended by the manufacturer, and, therefore, our study methods differed from those used by other authors. The Single Bond adhesive system used in a dry environment showed a higher bond strength result than the other materials, possibly due to its previous curing.

It is difficult to compare results of bond strength obtained in different studies because of the differences in tooth storage methodology, specimen preparation, cross-head speed and load, and storage of specimens before debonding. ${ }^{10}$

One of the factors that may affect the bond strength of adhesive systems is the storage time after specimen bonding. In this study, the shear bond strength trial was conducted 7 days after bonding, and the samples were stored in distilled water at $37{ }^{\circ} \mathrm{C}$ during that time. ${ }^{2,5}$ In other studies, shear bond strength trials were conducted 24 hours after bonding. ${ }^{3,4,11,17}$

The substrate used in our study was bovine tooth enamel, as in other studies., ${ }^{4,53,16}$ Bovine teeth are anatomically, histologically and chemically similar to human teeth, although bond strength result shows to be lower than those of human teeth. ${ }^{8,9}$

In this study, the samples used for the bond strength trial were cylinders made of Transbond ${ }^{\mathrm{TM}}$ $\mathrm{XT}$ composite resin. The objective of this study was to evaluate the interface between enamel-adhesivecomposite resin. Therefore, the use of a bracket would add another adhesive interface (composite resin-bracket base), which would add several variables; such as bracket material, retention system, form and structure of the bracket base.
The ARI score is used to evaluate enamel surface after debonding. A greater amount of remaining material means that the probability of damage to the enamel surface is lower. Adhesive fractures between the bracket and the composite resin are preferable because there is no enamel damage and the dentist can remove remnants without any risk of affecting the enamel. Damage to the enamel may occur in the case of cohesive fractures, which may be correlated ${ }^{14}$ or not ${ }^{6}$ with bond strength values.

In the Transbond ${ }^{\mathrm{TM}}$ MIP group with no contamination, a higher number of specimens had enamel damage, although this was not the group with the highest mean bond strength value. Other studies found higher bond strength results for Transbond ${ }^{\mathrm{TM}}$ MIP in dry environments, ${ }^{3}$ and some authors believed that they were higher than recommended for orthodontic bracket bonding. ${ }^{13}$

Therefore, not only bond strength, but also bonding characteristics, such as mechanisms and depth of penetration of different adhesives in the tags formed during enamel etching, are factors that should be evaluated and taken into consideration when making a decision about which materials to use.

Further studies should analyze bonding mechanism and the surface generated by these materials, both in dry environments and in cases of saliva contamination. Also, in vivo studies should test whether bond strength values in saliva contaminated environments are acceptable for orthodontic bracket bonding.

\section{CONCLUSIONS}

The results of this study showed that saliva contamination reduced bond strength significantly for the three adhesive systems tested, but there were no statistically significant differences between them when the groups with or without saliva contamination were compared, and they may be, therefore, considered as equivalent systems. 


\section{REFERENCES}

1. Artun J, Bergland S. Clinical trials with crystal growth conditioning as an alternative to acid-etch enamel pretreatment. Am J Orthod. 1984;85:333-40.

2. Bishara SE, Laffoon JF, Vonwald L, Warren J. Effect of time on the shear bond strength of cyanoacrylate and composite orthodontic adhesives. Am J Orthod Dentofacial Orthop. 2002;121(3):297-300.

3. Cacciafesta V, Sfondrini MF, Angelis M, Scribante A, Klersy C. Effect of water and saliva contamination on shear bond strength of brackets bonded with convencional, hydrophilic and self-etching primers. Am J Orthod Dentofacial Orthop. 2002;123(6):633-40

4. Cacciafesta V, Sfondrini MF, Angelis M, Scribante A, Klersy C. Effect of blood contamination on shear bond strength of convencional, hydrophilic primers. Am J Orthod Dentofacial Orthop. 2004;126(2):207-12.

5. Grandhi RK, Combe EC, Speidel TM. Shear bond strength of stainless steel orthodontic brackets with a moisture-intensive primer. Am J Orthod Dentofacial Orthop. 2001;119(3):251-5.

6. Hobson RS, Ledvinka J, Meechan JG. The effect of moisture and blood contaminationon bond strength of a new orthodontic bonding material. Am J Orthod Dentofacial Orthop. 2001;120(1):54-7.

7. Hormati AA, Fuller JL, Denehy GE. Effect of contamination and mechanical disturbance on the quality of acid-etched enamel. J Am Dent Assoc. 1980;100(1):34-8.

8. Nakamichi I, Iwaku M, Fusayama T. Bovine teeth as a possible substitutes in adhesion test. J Dent Res. 1983;62(10):1076-81.
9. Oesterie LJ, Shellhart WC, Belanger GK. The use of bovine enamel in bonding studies. Am J Orthod Dentofacial Orthop. 1998;114(5):514-9.

10. Pessoa CN, Souza ROA, Valença AMG, Nóbrega CBC, Mendes ACR, Nascimento $A B L$. Resistência ao cisalhamento de diferentes sistemas restauradores à dentina. Pesq Bras Odontoped Clin Integr. 2004;4(1):59-63.

11. Rajagopal R, Padmanabhan S, Gnanamani J. A comparison of shear bond strength and debonding characteristics of convencional, moisture-intensitive and selfetching primers in Vitro. Angle Orthod. 2004;74(2):264-8.

12. Reynolds IR. A review of direct orthodontic bonding. Br J Orthod. 1975;2(2):171-8.

13. Rosa CB, Pinto RAC, Habib FAL. Colagem ortodôntica em esmalte com presença ou ausência de contaminação salivar: é necessário o uso de adesivo autocondicionante ou de adesivo hidrofílico? Rev Dental Press Ortod Ortop Facial. 2008;13(3):34-42

14. Schaneveldt S, Foley TF. Bond strength comparison of moisture-insensitive primers. Am J Orthod Dentofacial Orthop. 2002;122(3):267-73.

15. Tortamano A, Naufi F, Nacaratto SRF, Vigorito JW. Avaliação do sistema adesivo ortodôntico MIP na presença de água e saliva. Ortodontia. 2001;34(3):66-9.

16. Webster MJ, Nanda RS, Duncanson MG, Khajotia SS, Sinha PK. The effect of saliva on shear bond strengths of hydrophilic bonding systems. Am J Orthod Dentofacial Orthop. 2001;119(1):54-8.

17. Zeppieri IL, Chung C, Mande FK. Effect of saliva on shear bond strength of an orthodontic adhesive used with moisture-intensitive and self-etching primers. Am J Orthod Dentofacial Orthop. 2002;124(4):414-9. 